\title{
ROUND TABLE DISCUSSION ON BAT-CONSERVATION - SUMMARY
}

\author{
by
}

\author{
A. PUNT \\ Dierfysiologisch Laboratorium der Universiteit van Amsterdam, The Netherlands
}

Under the chairmanship of dr. A. van Wijngaarden (Netherlands' Institute of Nature Research) a discussion on bat conservation was held. Seventeen speakers, representing 13 countries reported on the problems existing in various areas. Reports came from Van Wijngaarden and Braaksma (the Netherlands), Racey and Stebbings (United Kingdom), Gaisler (Czechoslovakia), Issel (Germany), Jensen (Denmark), Rydberg (Sweden, comments on the situation in Finland), Stock (situation in Belgium), Saint Girons (France), Dinale (Italy), Dulić (Yugoslavia), Mutere (Kenya), Lendell Cockrum, Myers, Koopman (U.S.A.), Greenhall (Mexico).

Summarizing, it turned out that urbanisation, the use of insecticides in agricultural areas and in summer roosts, large scale banding of bats by nonqualified people, amateur-speleology, and irresponsible bat control connected with the rabies and vampire problem, are the main causes of decrease in bat populations.

Alarming notes came from representatives of densily populated countries; causes are: restoration of summer roosts (old buildings, churches), old trees removed by forest conservation (reports from Braaksma, Issel), smoking out of church lofts, where nursing colonies are considered to be a nuisance, actions which cannot be prevented by lack of legislative protection of bats (Stebbings).

Even in those countries, where bats are under the protection of the law, the unpopularity of bats causes much damage to any colony found (Issel, Dulic, Jensen). Educational measures to make the people more bat-minded are urgently needed.

As to the winter roosts, in some cases much damage is done by banding by non-qualified people (reports from Stock and Racey, according to information from Belgium); by collecting, both for scientific (Saint Girons, Issel) and other pur- poses, collecting out of commercial interest included (Myers reported that 3000 bats were collected and sold at $\$ 3$ a piece!).

It is now well established, that damage through the use of insecticides is considerable. Those species, foraging in agricultural areas are largely diminished in numbers. In America a few years ago many dying bats were found. Investigation as to the cause of death was performed upon 200 of them. Though rabies infection was considered to be involved, it turned out, however, that insecticide poisoning caused this massacre (Lendell Cockrum). As the bio-mass of flying insects in England is estimated to be reduced by $50 \%$, this factor too may be the reason of decrease in bat populations (Stebbings).

On the other hand there were reports of no serious problems where forest-dwelling bats were concerned in Eastern Europe (Gaisler). The same holds for fruit eating bats (Mutere). An increase in number could even be noticed in those bats, which do not feed in agricultural areas (Lendell Cockrum, concerning Pipistrellus hesperus).

As to the rabies problem, Greenhall reported that in America incidence of rabies in bats is still rather low and cannot be considered a very serious public health problem.

As most of these topics are mentioned in the paper read by the representatives of Czechoslovakia, this report will follow as a conclusion of this summary.

The conference adopted the following resolution on bat conservation:

100 Scientists attending the 2nd International Bat Research Conference at Amsterdam on the 18th of March 1970 agreed upon the following resolution:

Bats are world wide and important in our ecosystem and to the human economy.

Delegates representing 20 nations stated that bats are declining, especially in highly urbanized areas. 
The main causes are : pollution by insecticides, loss of habitat, killing of bats by man.

Certain contries have recognized the importance of conserving bats and have legislation protection them. ${ }^{1}$ )

Since bats migrate internationally the conference recommends that other countries should provide legislation to protect these mammals.
Additionally it was agreed that further investigations in ecology of bats is essential for conservation, and any necessary control of local populations should be done by qualified persons.

1) Countries having protective legislation: Austria, Bulgaria, C.S.S.R, Denmark, D.B.R., D.D.R., Finland, Hungaria, Italy, Mexico, Poland, Switzerland, U.S.A. (Texas, Arizona, a.o.), U.S.S.R., Yugoslavia. 